\title{
Karbonhidrat ve Yă̆ Metabolizmasında D-alluloz (D-psikoz)
}

\author{
Mustafa ÖZGÜR 國, Aslı UÇAR 國
}

\section{ÖZ}

Değişen yaşam koşulları nedeniyle obezite ve obezite ile ilişkili endokrin hastalıkların görülme sıklığı artmıştır. Bu hastalıkların önlenmesinde yaşam tarzı değişikliklerine ek tedavi seçenekleri aranmaya başlamıştır. D-alluloz fruktozun 3. karbon epimeridir ve doğada nadiren bulunmaktadır. D- alluloz, güçlü antioksidan etkileri, bağırsak sindirim enzimlerine karşı inhibe edici aktivitesi, hepatik çekirdekten sitoplazmaya glukokinazın translokasyonu ve intestinal mukoza yoluyla glukozla rekabetçi transport gibi çeşitli mekanizmalar yoluyla aktivite göstermektedir. Ayrıca, yağların metabolizması ile ilgili olarak antihiperlipidemik, antihipertrigliseridemik etkileri de bulunmaktadır. D-alluloz ile ilgili ratlar üzerinde yapılan toksisite çalışmalarında herhangi bir yan etkisi gösterilmemiş ve güvenli olarak kabul edilmiştir. Oral yol ile alınan monosakkaritlerin emilimini azaltması, yağ asidi oksidasyonunu arttırırken, glukoz oksidasyonunu baskılaması gibi etkilerinden dolayı obezite ve ilişkili hastalıkların tedavisinde yaşam tarzı değişikliği ile beraber alternatif bir tedavi yöntemi olarak düşünülebilir.

Anahtar Kelimeler: Obezite; diyabet; karbonhidrat metabolizması; lipid metabolizması.

\section{D-allulose (D-psicose) in Carbohydrate and Lipid Metabolism}

\begin{abstract}
Due to changing living conditions, the incidence of obesity and endocrine diseases related to obesity has increased. In addition to lifestyle changes, alternative treatment options are being sought in the prevention of these diseases. Dallulose is the 3rd carbon epimer of fructose and is rarely found in nature. D-allulose shows activity through various mechanisms such as strong antioxidant effects, inhibitory activity against intestinal digestive enzymes, translocation of glucokinase from hepatic nucleus to cytoplasm and competitive transport by glucose through intestinal mucosa. In addition, there are antihyperlipidemic, antihypertriglyceridemic effects related to lipid metabolism. Toxicity studies on D-allulose-related rats did not show any side effects and were considered safe. Reducing absorption of oral monosaccharides can be thought of as an alternative treatment modality with obesity and lifestyle changes due to its effects such as suppressing glucose oxidation while increasing fatty acid oxidation.
\end{abstract}

Keywords: Obesity; diabetes mellitus; carbohydrate metabolism; lipid metabolism.

\section{GíRiş}

Teknolojinin hızla gelişmesi yaşam tarzı değişikliğini de beraberinde getirmiştir. Tarımsal faaliyetlerden sanayiye kadar, hatta günlük yapılan ev işlerinde bile makineleşmenin etkisi, insanların fiziksel aktivite düzeylerinde azalmaya yol açmıştır. Gelişen teknolojinin besin sanayinde de yaygın olarak kullanılması ile beslenme alışkanlıklarında da köklü değişiklikler meydana gelmiştir. Ancak bu değişim sağlığı olumsuz yönde etkileyecek şekilde gerçekleşmiş ve fiziksel aktivite düzeyinin azalmasına bağlı olarak çağın hastalığı olarak adlandırılan obezite ve obeziteye eşlik eden kronik endokrin hastalıkların prevalans ve insidansında ciddi bir artış meydana gelmiştir (1). Bütün dünyada olduğu gibi ülkemizde de obezite ve diyabet görüme sıklığı giderek artmıştır. Ülkemizde obezite görülme sılklğ $6-18$ yaş çocuklarda \%7.8-17.6 arasında değişmekte, 3-6 yaş çocuklarda ise \%13.8'dir (2). Yetişkinlerde ise obezite görülme sıklığı \%30.3’tür (1). Diyabet görülme sıklı̆̆ ise 6-18 yaş arası çocuklarda \%0.95 (3), yetişkinlerde ise \%13.7 (4) olup, endişe verici boyutlara ulaşmıştır. Yüksek yağ ve basit şeker içeren besinlerin tüketimindeki artış obeziteye neden olan 
temel faktörlerden pozitif enerji dengesine neden olmaktadır (5). Bu nedenle pozitif enerji dengesinin kontrolünün sağlanması için aspartam, asesülfam $\mathrm{K}$ gibi enerji içermeyen yapay tatlandırıcılar ile; sorbitol, ksilitol gibi düşük enerjili şeker alkollerinin tüketiminde artış meydana gelmiştir (6). $\mathrm{Bu}$ artışa rağmen obezite ve diyabet gibi kronik hastalıkların görülme sıklığının artmaya devam etmesi nedeniyle, Dünya Sağlık Örgütü, bu hastalıkların önlenmesinde enerji alımının azaltılmasına ek olarak fiziksel hareketsizliğin de azaltılması gerektiğini belirtmiştir (7). Sonuç olarak, yeterli ve dengeli beslenmeyi destekleyen yaşam tarzı değişiklikleri, obezite ve diyabet gelişimini önleyen temel beslenme tedavisi stratejileridir (8).

Son yıllarda, Uluslararası Nadir Şekerler Enstitüsü (International Institute of Rare Sugar) tarafindan "doğada nadir görülen monosakkaritler ve türevleri” olarak tanımlanan nadir şekerler üzerinde birçok çalışma yapılmaktadır. Antitümör bileşiklerin sentezlenmesinde D-arabinozun, antiinflamatuvar, antioksidan ve immün baskılayıcı aktiviteler gibi çeşitli biyolojik fonksiyonlarından dolayı D-allozun kullanılması nadir şekerler ile ilgili yapılan çalışmalara örnek teşkil etmektedir $(9,10)$. Doğada 50'den fazla nadir şeker bulunmaktadır. Çeşitli çalışma sonuçlarına göre karbonhidrat ve yağ metabolizması üzerinde etkileri bulunan D-alluloz bunlardan birisidir (11,13). Dallulozun güçlü antioksidan etkileri, bağırsak sindirim enzimlerine karşı inhibe edici aktivitesi, hepatik çekirdekten sitoplazmaya glukokinazın (GK) translokasyonu ve intestinal mukoza yoluyla glukozla rekabetçi transport gibi çeşitli mekanizmaları içeren aktiviteleri gösterilmiştir $(14,16)$. Bu derlemede D-alluloz bileşiğinin karbonhidrat ve yağ metabolizması üzerine etkilerinin incelenmesi amaçlanmıştır.

\section{D-allulozun Kimyasal Özellikleri}

D-allulozun kapalı formülü glukozun genel formülü ile aynı olup C6H12O6 şeklindedir. Sistematik adlandırması D-ribo 2-hekzuloz ve fruktozun 3. karbon atomu epimeri olan bir monosakkarittir (Şekil 1). D-alluloz ayrıca psikofuraninden izole edildiği için D-psikoz olarak da adlandirılmaktadır (17).

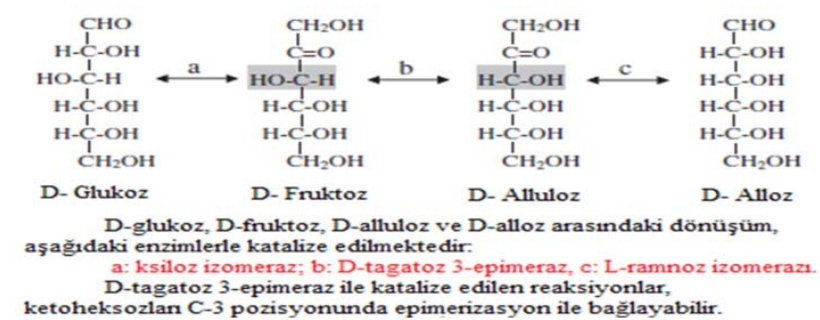

Şekil 1. D-glukozun D-alluloza enzimatik dönüşümü (17)

D-alluloz bileşiğine doğada özellikle Amerika kıtasında yaz aylarında yetişen bitkiler (Itea bitkisi) gibi bazı bitkilerin yapısal bileşeni (18) olarak ve nadiren de bakterilerde (19) rastlanmaktadır. Kokusuz beyaz bir toz olan D-alluloz, $25^{\circ} \mathrm{C}$ 'de (291g) hazırlanmaktadır. Suda kolaylıkla çözünebilmekte ve ağırlıkça \%74'lük bir çözelti elde edilmektedir. Kimyasal ve biyolojik özellikleri Tablo 1'de gösterilmiştir (20). Yapısında bir keton grubu bulunmakta ve indirgeyici ajan olarak görev yapmaktadır. D-allulozun tatlılığı, sükrozun yaklaşık \%70'i kadardır ve $96^{\circ} \mathrm{C}$ 'de eriyerek karamel (esmerleşme tepkimesi) oluşturmaktadır (21). Hayvan deneylerinde Dallulozun enerji değeri $0.007 \mathrm{kkal} / \mathrm{g}$ olarak saptanmıştır (22). İndirgeyici ajan olduğu için, 1sıl işlem sonucunda, D-glukoz veya D- fruktozdan daha düşük bir seviyede amino-karbonil reaksiyonunu (Maillard reaksiyonu) indüklemektedir (23).

Doğada nadiren bulunmasına rağmen, sükroz ya da Dglukoz izomerizasyonunun yanı sıra işlenmiş şeker kamışı ve pancarın hidrolizinden elde edilen D-glukoz ve D-fruktozun ticari karışımlarının küçük bir miktar Dalluloz içerdiği bildirilmiştir (24). Oshima ve arkadaşlarının (25) yaptığı bir çalışmada da, şeker içeriği yüksek olan besinlerin isitılması ile fruktozun enzimatik olmayan tepkimeleri sonucu D-alluloz oluştuğu rapor edilmiştir. $\mathrm{Bu}$ çalışmada çeşitli besinlerdeki D-alluloz içeriğinin $\quad 0.5-130.6 \mathrm{mg} / 100 \mathrm{~g}$ arasında değiştiği bildirilmiştir. D-fruktozu D-alluloza dönüştüren anahtar enzim D-tagatoz 3-epimerazın keşfinden sonra ise ticari olarak üretilmektedir (26).

D-alluloz ayrica 1,2: 4,5-di-O-izopropiliden- $\beta$ Dfruktopiranozdan molibdat iyon katalizörlüğünde kimyasal sentez yolu ile çok daha düşük bir maliyetle üretilmekte ve kullanılmaktadır. D-alluloz, 2014 yılında Amerika Birleşik Devletleri (ABD) Gıda ve İlaç Dairesi (FDA) tarafından "genel olarak güvenli" (GRAS) kabul edilmiş (GRAS Bildirisi No. GRN 400) ve çeşitli besinlerde takviye edici bir bileşen olarak kullanılmasına izin verilmiştir. Ancak günümüzde bilindiği kadarıyla sadece Japonya ve Güney Kore'de ticari olarak üretilmektedir (21).

Tablo 1. D-allulozun kimyasal ve biyolojik özellikleri $(20,21)$

\begin{tabular}{|c|c|}
\hline Özellik & Değer \\
\hline Kimyasal Ailesi & $\begin{array}{l}\text { Karbonhidrat ketohegsoz, D- } \\
\text { fruktozun 3-epimeri }\end{array}$ \\
\hline Molekül formülü & $\mathrm{C}_{6} \mathrm{H}_{12} \mathrm{O}_{6}$ \\
\hline Molekül ağırlığı & $180.156 \mathrm{~g} / \mathrm{mol}$ \\
\hline Fiziksel formu & Beyaz katı kristal \\
\hline Koku & Yok \\
\hline Erime sıcaklığ1 & $96^{\circ} \mathrm{C}$ \\
\hline Optik rotasyon & $(\alpha)^{20} / \mathrm{D}=-85^{\circ} \mathrm{C}\left(\mathrm{c}=1, \mathrm{H}_{2} \mathrm{O}\right)$ \\
\hline Çözünürlük & $25^{\circ} \mathrm{C}^{\prime}$ de $\% 74^{\prime} l u ̈ k, 50^{\circ} \mathrm{C}^{\prime}$ de $\% 83^{\prime} l u ̈ k$ \\
\hline Bağıl tatlılık & $\begin{array}{l}\text { \%10’luk çözeltide sükrozun \%70’i } \\
\text { kadar }\end{array}$ \\
\hline Enerji & $0.007 \mathrm{kkal} / \mathrm{g}$ (hayvan çalışmaları) \\
\hline $\begin{array}{l}\text { Maillard } \\
\text { reaksiyonu }\end{array}$ & Evet \\
\hline Toksisite & Hayır (Hayvan çalışmaları) \\
\hline
\end{tabular}

g: gram, kkal: kilokalori

\section{D-allulozun Metabolizması}

D-alluloz ve L-monosakkarit ve D-tagatoz izomerleri, alternatif tatlandırıcılar olarak kullanılmaya başlanmıştır (27). Ancak, D-allulozun metabolizması gösteren çalışmaların sayısı yetersizdir (28). Yapılan bir çalışmada oral olarak D-alluloz enjekte edilen aç ratların idrar, feçes, nefes ve organ dokularında bileşiğin tamamen korunduğu saptanmıştır. Bu nedenle, metabolize olabilse bile enerji olarak çok az kullanıldığı düşünülmektedir (22). 
D-allulozun, ratlarda ince bağırsak tarafindan emildiği saptanmıştır. Emilen D-alluloz, kan dolaşımına geçerek idrarla atılmaktadır. Bir çalışmada, D-allulozun ratlarda küçük bir kısmının ince bağırsaktan emilmeden kalın bağırsağa geçerek (29), insanlarda ise çok daha küçük bir kısmın fermente olduğu belirtilmiştir (30). Yapılan bir çalışmada oral yolla alınan D-allulozun idrardaki konsantrasyonları 60. ve 120. dakikalarda sirasıly \%19 ve \%37 olarak belirlenmiştir (31).

D-glukozun bağırsak lümeninden enterositlere alınmasına, aktif taşıyıcı sodyum bağımlı glukoz kotransporter 1 (SGLT1) aracılık etmektedir. Bu taşınma için gereken enerji bazolateral membran üzerinde bulunan $\mathrm{Na}+/ \mathrm{K}+$ pompasi tarafindan tutulan sodyum elektrokimyasal potansiyel gradyanı ile sağlanmaktadır (Şekil 2) (32). D-glukozun aksine, D-alluloz, D-fruktoz taşıyıcı olarak bilinen pasif glukoz taşıyıcı 5 (GLUT5) tarafından enterositlere girmektedir. GLUT5, D-fruktoz için yüksek özgüllüğe sahip tek GLUT proteinidir ve Dalluloza yüksek afinitesi bulunmaktadır (33). Ayrıca, GLUT 2'nin de D-alluloz taşıdığı gösterilmiştir (32). Bu taşıyıcılar, ince bağırsak dışında çeşitli dokularda ve hücrelerde de eksprese edilmektedir. Bu durum, Dallulozun GLUT5 ve GLUT2 aracılığıyla çeşitli doku ve hücrelere girebildiğini göstermektedir (14). D-allulozun 30, 60 ve 120. dakikalarda gastrointestinal sistemdeki konsantrasyonları sirasiyla $\% 67, \% 50$ ve $\% 26$ olarak tespit edilmiştir. Karaciğerdeki D-alluloz seviyeleri 30, 60 ve 120. dakikada sirasiyla $126.3 \pm 45.0,200 \pm 86.3$ ve $127.5 \pm 32.6 \mu \mathrm{g} / \mathrm{g}$ bulunurken; akciğer timüs, dalak, kalp, beyin ve kas dokusunda daha düşük seviyelerde olduğu belirtilmiştir (31).

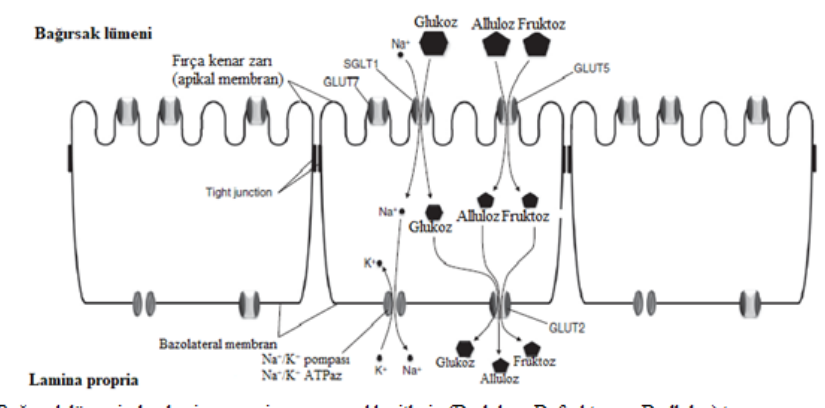

Bağırsak lümeninden lamina propriaya monosakkaritlerin (D-glukoz, D- fruktoz ve D-alluloz) taşınma yolu. D-allulozun hücre içine alımına GLUT5 aracillk eder ve GLUT2 tarafindan taşııır. SGLT1: Sodyum bağımil glukoz taşıyıc1, GLUT2: Glukoz taşıyıc1 2, GLUT5: Glukoz taşı̧yıc1 5, GLUT7 Glukoz taşıyıı 7

Şekil 2. D-allulozun hücre içine taşınması (14)

Daha önce D-allulozun çeşitli mekanizmaları içeren aktiviteleri olduğu belirtilmiştir (14). D-alluloz ayrıca ilk antelmintik (bağırsak solucanlarını düşürücü ya da öldürücü etki) şeker olarak tanımlanmıştır ve parazit büyümesinin inhibisyonu üzerinde bazı olumlu etkiler gösterdiği bildirilmiştir (34). Yapılan çalışmalarda adipoz dokuda azalmaya neden olduğu, bu nedenle anti-obezite etkisinin olduğunu gösteren çalışmalar da bulunmaktadır $(13,35,36)$. Bu etkisinin yağ asidi ve karbonhidratların oksidasyonunu azaltması ile ilişkili olduğu düşünülmektedir (37).

D-allulozun Glukoz Metabolizması Üzerine Etkileri Besin alımından 120 dakika sonra D-alluloz, D-glukoz ve D-fruktozun Sıvı çözeltilerinin hücre içine emilim hızlarına bakıldığında D- alluloz ve D-fruktozun \%60'ının, glukozun ise sadece \%10'unun emilebildiği saptanmıştır. Ayrıca, ortamda bulunan diğer monosakkaritlerin glukozun emilme hızını azalttığ bilinmektedir. Aynı miktardaki (30mM) D-alluloz, glukozun emilim hızında \%56'lık bir azalma oluşturmaktadır. $\mathrm{Bu}$ durum bu şekerlerin hücre içine alınması sırasında bazolateral membran taşıyıcı GLUT2 yoluyla taşınırken birbirleriyle rekabet etmeleri ile açıklanmaktadır (14). D-alluloz, D-glukoz ve Dfruktozun bazolateral GLUT2'de taşınmasını rekabetçi bir şekilde inhibe edebilmesi, sindirim sisteminde Dglukoz ve D-fruktozun emiliminin azalmasina neden olabilmektedir. GLUT2 ve GLUT5, bağırsakta ve diğer dokularda ve hücrelerde dağıtılmaktadır. GLUT 2 esas olarak hepatositler, böbrek, ince bağırsak ve insülin üreten $\beta$ hücrelerin bazolateral membranında (38), GLUT 5 ise böbrek, adipoz doku, iskelet kası, beyin ve spermde eksprese edilmektedir (39). D-allulozun, bu doku ve hücrelerde GLUT2 veya GLUT5'e bağlanarak Dglukozun alımını kısmen inhibe edebileceği düşünülmektedir. D-glukoz ve D-fruktozun alımı üzerine metabolize olmayan D-allulozun baskılayıcı etkisi, insülin direncinin ve vücut adipoz dokusunun artışının engellenmesi gibi önemli biyolojik fonksiyonlarına katkıda bulunmaktadır (12).

D-allulozun karbonhidrat veya glukoz metabolizması üzerine bir diğer etkisi karaciğerde glukozun kullanımını arttıran hepatik GK'nin indüklenmesidir. D-allulozun katalitik mekanizma yoluyla GK aktivitesini arttırdığ1 saptanmıştır (15). Karaciğerde glukoz metabolizması, çekirdek ve sitoplazma arasındaki GK'nin aktivasyonu ile düzenlenmektedir. GK, glukoz homeostazının devamlılığını sağlayan ve glukolizin hız kısitlayıcı basamağı olan glukozun glukoz-6-fosfat'a fosforilasyonunu katalizleyen bir enzimdir (40). Düşük glukoz konsantrasyonlarında glukokinaz düzenleyici protein (GKRP) aktif olduğu için, glukokinaz inaktiftir. Düşük fruktoz konsantrasyonlarında GK, GKRP'den ayrışmakta ve GK'nin sitoplazmaya translokasyonunu sağlamaktadır (41). Glukolizde hız kısıtlayan bir diğer basamak ise fosfoenolpiruvat karboksikinaz (PEPCK) basamağıdır. $\mathrm{Bu}$ enzimlerin her ikisi de hepatik glukoneojenik yolaktaki hı sınırlayıcı basamakları düzenlemektedir. $\mathrm{Bu}$ nedenle diyabette hiperglisemiye neden olmaktadır (42). D-alluloz içeren bir diyetle beslenen ratlarda glukoz-6-fosfataz aktivitesi önemli ölçüde azalmıştır. PEPCK aktivitesinde etkileri tam olarak açıklanamamasına rağmen kan glukozunun homeostazı ile ilgili etkileri ortaya konmuştur (37).

Tip 2 Diyabet (T2DM), karaciğerde glukoz üretiminin ve glukozun subnormal postprandiyal klirensini içeren hepatik glukoz metabolizmasının bozulması ile ilişkilidir. Bunun nedeni, hepatik glukoz üretiminin baskılanmasının gecikmesi ve glukozun glikojene dönüşümünün bozulmasıdır (12). Glukokinaz translokasyonunun bozulması, hepatik glukoz kullanımının (glikojen depolanması ve glukoliz) baskılanmasına ve diyabetik sıçanlarda hepatik glukoz çıkışının hızlanmasına neden olarak hipergliseminin gelişmesine neden olmaktadır (43). $\mathrm{Bu}$ nedenle, GK'nin çekirdeğin dışına translokasyonunun uyarılmasının, T2DM'de hipergliseminin önlenmesinde yeni bir yaklaşım olabileceği düşünülmektedir (44). 


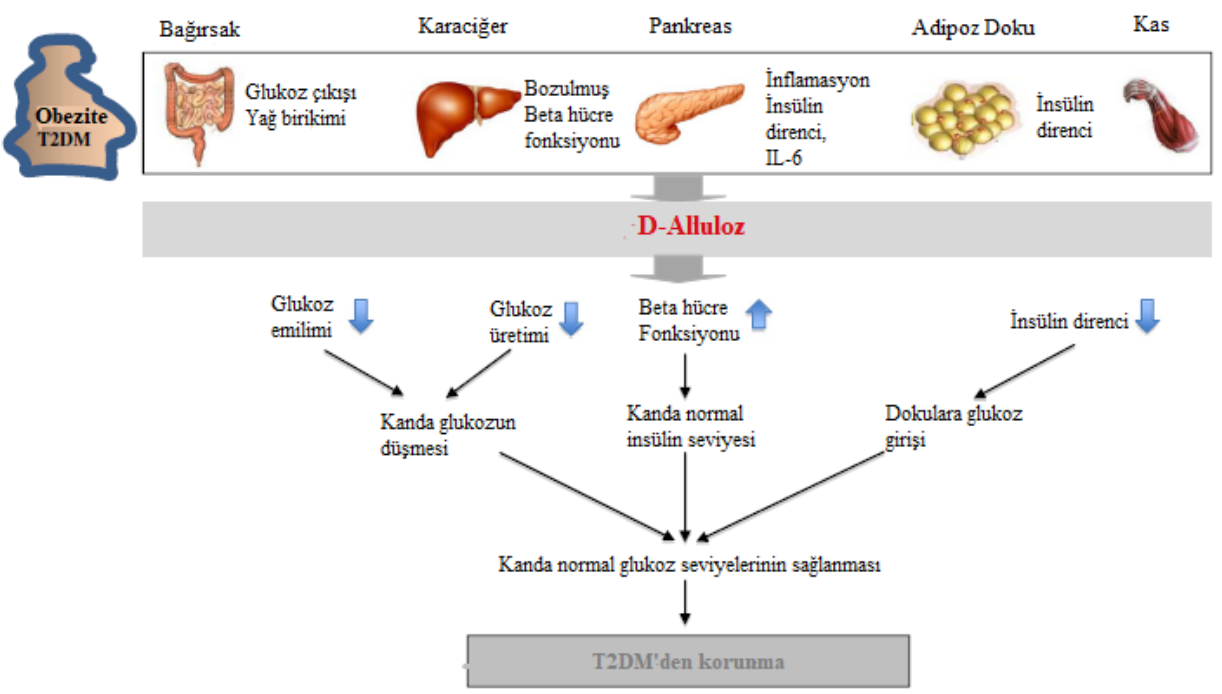

Şekil 3. D-allulozun T2DM üzerine etkisi (14)

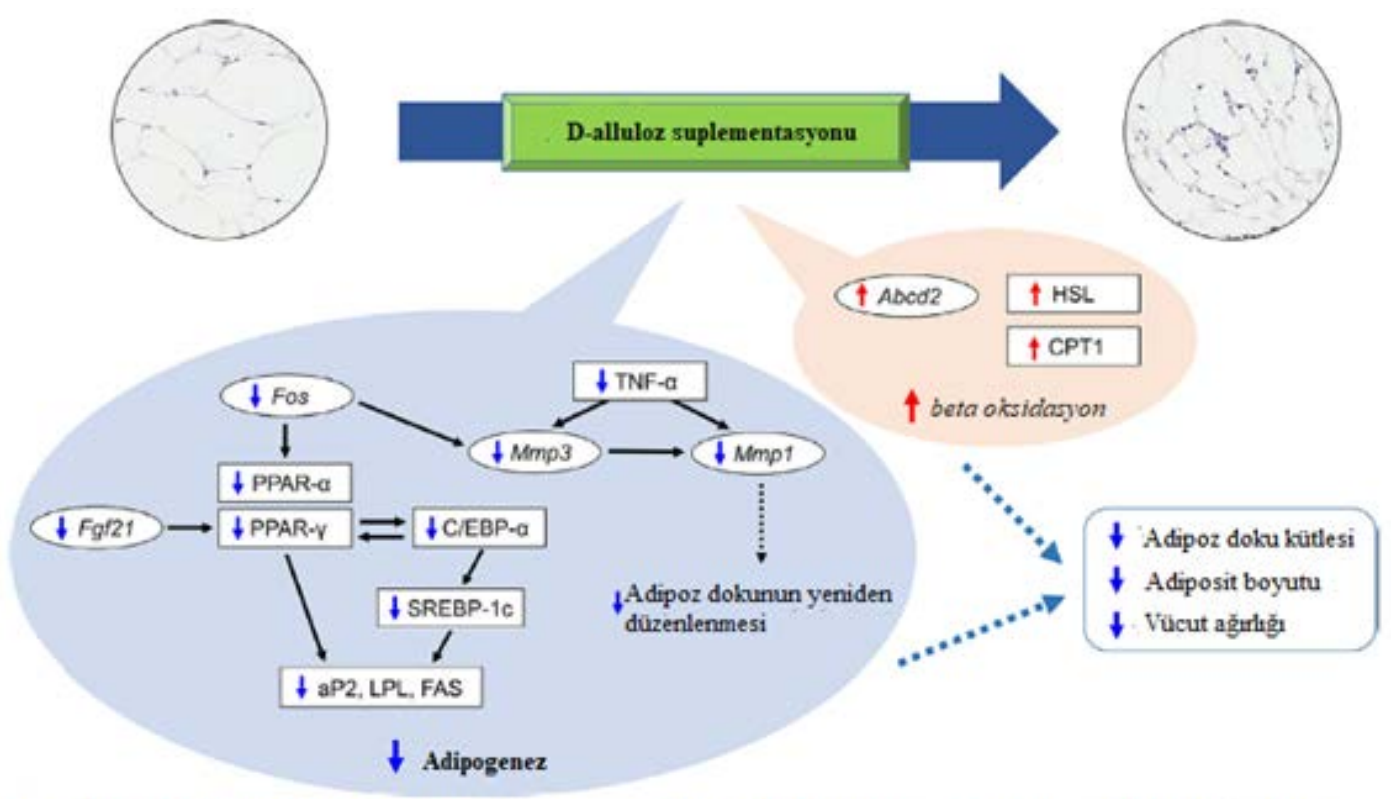

Abed2:ATP-binding cassette, sub-family D, HSL: hormona duyarh lipaz, CPT1: Kamitin palmitoltransferaz 1, TNF-a: Tümör nekrözis faktör alfa, Fos: FBJ murin osteosarkom viral onkojen homologu, PPAR-a: peroksizom proliferatör aktive edici reseptör alfa, PPARgama: peroksizom proliferatör aktive edici reseptör gama, Fdf21: fibroblast büyùme faktörü 21, C/EBP-alfa: CCAAT güçlendinci bağlayıa protein-alfa, SREBP-1c: sterol düzenleyici element bağlayıca protein-1c, aP2: adiposit protein 2, LPL: lipoprotein lipaz, FAS: yağ asid sentaz

Şekil 4. D-alluloz suplementasyonunun adipoz doku metabolizması üzerine etkisi (53)

D-allulozun D-fruktoz ile aynı şekilde emildiği (29) ve ketoheksokinaz ile D-alluloz-fosfata fosforile edildiği gösterilmiştir (45). Toyoda ve arkadaşları, D-allulozun, Goto-Kakizaki farelerinin ve Wistar sıçanlarının (kontrol) karaciğerindeki D-fruktoz ile aynı mekanizmayı kullanarak GK'nin translokasyonunu uyardığını göstermiştir. Ayrıca, D-allulozun, glukoz yüklemesinden sonra plazma glukoz seviyelerindeki artışı baskıladığı rapor edilmiştir (46). Bu sonuçlar, D-allulozun, GK translokasyonunu önemli ölçüde uyardığını, sitoplazmada GK ile artan glukoz fosforilasyonuna yol açtığını ve böylece glikojen depolanmasını arttırdığını göstermektedir.
D-allulozun, T2DM ve obezite üzerine etkileri Șekil 3'te gösterilmiştir. D-Allulozun, obezite ve T2DM'nin önlenmesinde birden fazla rolü bulunmaktadır. İnflamatuvar makrofajların adipositlere infiltrasyonu ve buna bağlı olarak hem makrofajlardan hem de adipositlerden inflamatuvar sitokinlerin salınması ile adipoz dokuda büyüme meydana gelmekte, böylece obezite ve/veya T2DM'ye yol açmaktadır (47). T2DM'ye bağlı olarak gelişen hiperglisemi durumunda, pankreatik beta hücreleri artmış kan glukoz seviyelerini azaltmak için insülin üretmede yetersiz kalmaktadır. Bu durum beta hücre yetmezliği, glukoz intoleransı ve T2DM'ye bağlı ilerleyen adacık hipertrofisi ile sonuçlanmaktadır. 
Ayrıca, karaciğerden glukoz çıkışı artmakta, yağ dokuları ve iskelet kaslarında glukoz kullanımı azalmaktadır (48). D-allulozun hiperglisemiyi düşürücü etkisi, inflamasyona uğramış adipositlerden salınan proinflamatuvar adipositokinlerin baskılanmasıyla olmaktadır. Ratlar üzerinde yapılan bir çalışmada 12 hafta boyunca yüksek yağlı diyet ile beslenen grup ile yüksek yağlı diyete ek olarak \%3'lük D-alluloz alan grubun plazma adipokin ve sitokin seviyeleri karşılaştırılmıştır. Çalışmanın sonucunda D-alluloz alan grupta yüksek yağlı diyet ile beslenen gruba kıyasla interlökin $1 \beta$ (IL-1 $\beta$ ) seviyelerinin istatistiksel olarak daha düşük olduğu saptanmıştır (49). D-alluloz, proinflamatuvar adipositokinlerin baskılanmasıyla pankreatik adacık hücrelerini korumakta, insülin üretiminin yeniden başlatılmasını sağlamakta, bağırsak glukoz emilimini azaltmakta, adipoz ve kas dokuları tarafindan glukoz alımını arttırmaktadır (14).

D-allulozun Yă̆ Metabolizması Üzerine Etkileri

Son yıllarda fruktoz içeren sükroz veya yüksek fruktozlu mısır şurubu ile tatlandirılmış içeceklerin aşırı tüketiminin obezitenin nedenlerinden biri olduğu düşünülmektedir (50). Fruktozun lipojenik etki gösterdiği ve metabolik sendrom gelişimi ile ilişkili olduğu belirtilmektedir (51). Bu nedenle fruktozun epimeri olan D-allulozun da lipojenik olduğu yönünde düşünceler ortaya atılmış, ancak D-allulozun anti hiperlipidemik ve anti-obezite etkilerinin olduğu saptanmıştır (31). Ratlar üzerinde yapılan bir çalışmada 18 ay boyunca \%3'lük Dalluloz içeren bir diyetle beslenmenin sakkaroz içeren bir diyetle beslenmeyle karılaştırıldığında, enerji alımında fark olmamasına rağmen abdominal yağlanmayı ve total vücut yağını azalttığı saptanmıştır (37). Yapılan başka bir çalışmada da \%5'lik D-alluloz içeren bir diyetin total vücut yağını ve abdominal yağlanmayı azalttığ bildirilmiştir (11). Hossain ve arkadaşlarının (12) yaptığ çalışmada da T2DM'si olan OLETF ratlarında içme sularına eklenen \%5'lik D-allulozun kontrol grubuna kıyasla hem abdominal yağlanmayı hem de total vücut yağını önemli ölçüde azalttığı rapor edilmiştir. Ayrıca, yüksek yağlı diyet ile beslenen ratlarda farklı dozlarda verilen D-allulozun doza bağımlı olarak daha az ağırlık kazanımına neden olduğu saptanmıştır (36). D-allulozun anti-obezite etkisinin bir sonraki öğünde besin alımındaki azalmadan kaynaklı olduğu düşünülmektedir $(13,52)$. Bu düşünceye ek olarak daha fazla yağ, daha az karbonhidrat oksidasyonuna neden olarak 24 saatlik enerji harcamasını arttırdığı saptanmıştır (37). D-alluloz suplementasyonun adipoz doku metabolizması üzerindeki etkisinin şematik diyagramı Şekil 4'te gösterilmiştir (53).

D-allulozun lipojenik etkilerinden dolayı antihipertrigliseridemik etkilerinin de olabileceği düşünülmüş, ancak yeterli kanıt henüz ortaya konmamıştır. Matsuo ve arkadaşlarının (11) yaptığı bir çalışmada, kontrol diyeti ile karşılaştırıldığında \%5'lik Dalluloz içeren diyetin 8 hafta sonra plazma trigliserid (TG) seviyesini düşürdüğü bildirilmiştir. Aynı araştırmacıların daha sonra yaptığı çalışmada ise 12 ay boyunca D-alluloz içeren diyetle beslenen ratlarda, kontrol grubuna kiyasla plazma TG seviyelerinde istatistiksel olarak anlamlı farklılık olmadığı saptanmıştır (36). Nagata ve arkadaşlarının (37) yaptığı çalışmada da, D-alluloz içeren diyetin kontrol diyeti ile karşılaştırıldığında plazma TG seviyelerinde fark oluşturmadığı, hepatik TG seviyelerinin ise kontrol grubuna göre daha düşük olduğu rapor edilmiştir. Baek ve arkadaşlarının (54) yaptıkları çalışmada ise $\mathrm{db} / \mathrm{db}$ farelerinin diyetine 28 gün boyunca eklenen D-allulozun plazma TG seviyelerinde istatistiksel olarak anlamlı farklılığa yol açmadığını belirtmişlerdir. Karaciğerdeki lipojenik enzimlerin (yağ asidi sentaz, glukoz-6-fosfat dehidrogenaz) D-alluloz alımına bağlı olarak azalması, ince bağırsakta lipit metabolizmasını modüle eden (SREBP-1c) gen ekspresyonunun olması D-allulozun anti-hipertrigliseridemik aktiviteleri olacağını gösterse de halen kanıt düzeyinde çalışmalara ihtiyaç bulunmaktadır (55).

D-allulozun kolesterol metabolizması üzerine etkilerini inceleyen bir çalışmada kontrol grubuna göre D-alluloz içeren diyet ile beslemenin serum kolesterol seviyesini önemli ölçüde azalttığı görülmektedir (37). Fakat yapılan başka bir çalışmada D-alluloz ile beslenen $\mathrm{db} / \mathrm{db}$ farelerindeki plazma kolesterol seviyeleri, 28 günlük kontrol diyetiyle beslenen farelerden farklı olmadığı rapor edilmiştir (54). Diyetle indüklenen obez farelerde D-alluloz içeren diyet ile beslenmenin, TG düzeylerinde önemli değişlik yapmamasına karşın serum kolesterol seviyelerinde artışa neden olduğu saptanmıştır (26). Nagata ve arkadaşlarının (37) yaptığı çalışmada Dallulozun, kolesterol sentezi için gerekli olan hepatik 3hidroksil-3-metilglutaril-koenzim A'nın (HMG-CoA) gen ekspresyonu üzerinde anlamlı bir etkisi bulunmamıştır. Halen, D-alluloz ve kolesterol metabolizması arasındaki ilişkide hiçbir somut veri bulunmamaktadır. Bununla birlikte, D-allulozun anti-hiperlipidemik etkisini açıklığa kavuşturmak için, lipid metabolizmasını (emilim, sentez, taşınma, alım ve klirens) etkileyen faktörler hakkında daha fazla araştırma yapılması gerektiği düşünülmektedir (14).

\section{Toksisitesi}

Matsuo ve arkadaşlarının (56) ratlar üzerinde yaptığı bir çalışmada 14 gün boyunca oral yoldan farklı miktarlarda verilen D-allulozun akut ve subkronik etkileri incelenmiş, diyette toplam enerjinin \%40'1n üzerinde D-alluloz suplementasyonunun ince bağırsak lümeni için zararlı etkisinin olduğu rapor edilmiştir. Ratlarda yapılan bir başka çalışmada ise \%3'lük D-alluloz içeren diyetin uzun sürede (18 ay) herhangi bir olumsuz etkisinin olmadığ 1 saptanmıştır (38). Ancak, \%50 oranında D-alluloz içeren diyetin öldürücü doz olduğu, bu dozun ratlar için $16.3 \mathrm{~g} / \mathrm{kg}$ olduğu bildirilmiştir (56). Bu nedenle toksisite derecelendirme kategorisine göre 'nispeten zararsı' olarak değerlendirilmektedir (21). Henüz yeterli çalışma olmamasına rağmen D-alluloz'un toksik olmayan enerji içermeyen bir tatlandırıcı olduğu düşünülmektedir. Sağlıklı insanlar için $0.55 \mathrm{~g} / \mathrm{kg}$ 'nin herhangi bir yan etki göstermeyen doz olduğu belirtilmiştir. (30).

\section{SONUC}

Bütün dünya ülkelerinde olduğu gibi ülkemizde de obezite ve obeziteye bağlı endokrin hastalıkların görülme sıklığı giderek artmaktadır. Günümüzde en önemli sağlık sorunlarından biri olan obezitenin önlenmesinde ve tedavisinde multi-disipliner çalışmalar yapılmaktadır. Bununla ilgili güncel çalışmaların odak noktalarından biri de yüksek enerji içeren besinler yerine bunların düşük enerjili muadillerinin geliştirilmesidir. D-alluloz, 
Güneydoğu Asya'da bulunan bir bitkinin (Itea) yaprağında doğal olarak bulunan ve çeşitli enzimatik tepkimeler sonucu yapay olarak elde edilebilen bir monosakkarittir. Çok düşük enerji içermesinin yanı sıra, glukoz ve diğer monosakkaritlerin emiliminin azalmasında, hiperglisemi durumunda glukozun fosforilasyonu sağlayarak kan şekerinin regülasyonunda ve yă asitlerinin beta oksidasyonunun artmasındaki etkilerinden dolayı, başta obezite olmak üzere T2DM ve metabolik sendrom gibi karbonhidrat ve yağ metabolizmasının bozulduğu endokrin hastalıklarda alternatif tedavi seçeneği olarak düşünülmeye başlamıştır. Bununla birlikte besin sanayinde D-alluloz içeren beslenme ürünleri geliştirilebilir ve tüketime sunulabilir. Ancak obezite ve obeziteye bağlı hastalıkların önlenmesinde en etkili yöntem, DSÖ’nün önerdiği gibi fiziksel aktivitenin arttırılması ve yeterli ve dengeli beslenme planının olduğu yaşam tarzı değişikliğidir. Dallulozun karbonhidrat ve yağ metabolizmasında sağlığa yararlı etkileri açıklanmış olsa da, yaşam tarzı değişikliği ile beraber alternatif bir tedavi yöntemi olduğu unutulmamalıdir.

\section{KAYNAKLAR}

1. TC Sağlık Bakanlığı Türkiye Halk Sağlığı Kurumu. Türkiye sağlıklı beslenme ve hareketli hayat programı. Ankara: Sağlık Bakanlığı; 2013.

2. Bereket A, Atay Z. Current status of childhood obesity and its associated morbidities in Turkey. Journal of Clinical Research in Pediatric Endocrinology. 2012; 4(1): 1-7.

3. Yeşilkaya E, Cinaz P, Andıran N, Bideci A, Hatun Ş, Sarı E ve ark. First report on the nationwide incidence and prevalence of Type 1 diabetes among children in Turkey. Diabetic Medicine. 2017; 34(3): 405-10.

4. TURDEP Çalışma Grubu. TURDEP-2 sonuçlarının özetleri. Satman I. 32. TEMD Kongresi; 2010; Antalya.

5. Giugliano D, Esposito K. Mediterranean diet and metabolic diseases. Current Opinion in Lipidology. 2008; 19(1): 63-8.

6. Borges M C, Louzada M L, de Sá T H, Laverty AA, Parra DC, Garzillo JMF, et al. Artificially sweetened beverages and the response to the global obesity crisis. PLoS medicine. 2017; 14(1): e1002195.

7. WHO. Noncommunicable diseases and their risk factors. London: The Lancet Global Health; [Updated: 5 Sep 18; Cited: 26 Sep 18] Available from: http://www.who.int/ncds/prevention/physicalactivity/lancet-global-health-insufficient-physicalactivity-2001-2016/en/.

8. Asif $M$. The prevention and control the type-2 diabetes by changing lifestyle and dietary pattern. Journal of Education and Health Promotion. 2014: 3(1): 1-8. doi: 10.4103/2277-9531.127541.

9. Nagata Y, Mizuta N, Kanasaki A, Tanaka K. Rare sugars, d-allulose, d-tagatose and d-sorbose, differently modulate lipid metabolism in rats. Journal of the Science of Food and Agriculture. 2018; 98(5): 2020-6.

10. Yan Tang S. Rare Sugars: Applications and Enzymatic Production. Biocatalysis and Biotransformation. 2012; 1(2): 363-8.

11. Matsuo T, Izumori K. Effects of dietary D-psicose on diurnal variation in plasma glucose and insulin concentrations of rats. Bioscience, Biotechnology, and Biochemistry. 2006; 70(9): 2081-5.

12. Hossain M A, Kitagaki S, Nakano D, Nishiyama A, Funamoto Y, Matsunaga T. Rare sugar D-psicose improves insulin sensitivity and glucose tolerance in type 2 diabetes Otsuka Long-Evans Tokushima Fatty (OLETF) rats. Biochemical and Biophysical Research Communications. 2011; 405(1): 7-12.

13. Iida T, Yamada T, Hayashi N, Okuma K, Izumori K, Ishii R. Reduction of abdominal fat accumulation in rats by 8-week ingestion of a newly developed sweetener made from high fructose corn syrup. Food Chemistry. 2013; 138(2-3): 781-5.

14. Hossain A, Yamaguchi F, Matsuo T, Tsukamoto I, Toyoda Y, Ogawa M, et al. Rare sugar D-allulose: Potential role and therapeutic monitoring in maintaining obesity and type 2 diabetes mellitus. Pharmacology and Therapeutics. 2015; 155: 49-59.

15. Braunstein C, Noronha J, Glenn A, Viguiliouk E, Noseworthy R, Khan, T, Kendall C, et al. A doubleblind, randomized controlled, acute feeding equivalence trial of small, catalytic doses of fructose and allulose on postprandial blood glucose metabolism in healthy participants: The Fructose and Allulose Catalytic Effects (FACE) Trial. Nutrients. 2018; 10(6): 750.

16. Kishida K, Iida T, Yamada T, Ferraris RP, Toyoda Y. Intestinal D-allulose transport is likely mediated by Glucose Transporter Type 5 (GLUT5). The FASEB Journal. 2018: 32(Suppl 1); 757-1.

17. Eble T E, Hoeksema H, Boyack G A, Savage G M. Psicofuranine. I. Discovery, isolation, and properties, Antibiotics and Chemotherapy. 1959; 9(7): 419-20.

18. Poonperm W, Takata G, Ando Y, Sahachaisaree V, Lumyong P. Efficient conversion of allitol to Dpsicose by Bacillus pallidus Y25. Journal of Bioscience and Bioengineering. 2007; 103(3): 282-5.

19. Zhang L, Mu W, Jiang B, Zhang T. Characterization of D-tagatose-3-epimerase from Rhodobacter sphaeroides that converts D-fructose into D-psicose. Biotechnology Letters. 2009; 31(6): 857-62.

20. Fukada K, Ishii T, Tanaka K, Yamaji, Yamaoka Y, Kobashi KI, et al. Crystal structure, solubility, and mutarotation of the rare monosaccharide D-psicose. Bulletin of the Chemical Society of Japan. 2010; 83(10): 1193-7.

21. Mu W, Zhang W, Feng Y, Jiang B, Zhou L. Recent advances on applications and biotechnological 
production of D-psicose. Applied Microbiology and Biotechnology. 2012; 94(6): 1461-7.

22. Matsuo T, Suzuki H, Hashiguchi M, Izumori K. DPsicose is a rare sugar that provides no energy to growing rats. Journal of Nutritional Science and Vitaminology. 2002; 48(1): 77-80.

23. Sun Y, Hayakawa S, Izumori K. Modification of ovalbumin with a rare ketohexose through the Maillard reaction: Effect on protein structure and gel properties. Journal of Agricultural and Food Chemistry. 2004; 52(5): 1293-9.

24. Thacker J, Toyoda Y. Lung and heart-lung transplantation at University of Pittsburgh: 19822009. Clinical Transplants. 2009; 179-95.

25. Oshima H, Kimura I, Izumori K. Psicose contents in various food products and its origin. Food Science and Technology Research. 2006; 12(2): 137-43.

26. Izumori K. Izumoring: A strategy for bioproduction of all hexoses. Journal of Biotechnology. 2006; 124(4): 717-22.

27. Livesey G. The energy values of unavailable carbohydrates and diets: an inquiry and analysis. The American Journal of Clinical Nutrition. 1990; 51(4): 613-37.

28. Cree GM, Perlin AS. Isopropylidene derivatives of Dallulose (D-psicose) and D-erythro-hexopyranose 2, 3-diulose. Canadian Journal of Biochemistry and Physiology. 1968; 46(8): 765-0.

29. Matsuo T, Tanaka T, Hashiguchi M, Izumori K, Suzuki H. Metabolic effects of D-psicose in rats: studies on faecal and urinary excretion and caecal fermentation. Asia Pacific Journal of Clinical Nutrition. 2003; 12(2): 225-31.

30. Iida T, Hayashi N, Yamada T, Yoshikawa Y, Miyazato S, Kishimoto Y, et al. Failure of D-psicose absorbed in the small intestine to metabolized into energy and its low large intestinal fermentability in humans. Metabolism - Clinical and Experimental. 2010; 59(2): 206-14.

31. Tsukamoto I, Hossain A, Yamaguchi F, Hirata Y, Dong Y. Kamitori K, Intestinal absorption, organ distribution, and urinary excretion of the rare sugar Dpsicose. Drug Design, Development and Therapy. 2014; 8: 1955-64.

32. Hishiike T, Ogawa M, Hayakawa S, Nakajima D, O'Charoen S, Ooshima $\mathrm{H}$, et al. Transepithelial transports of rare sugar D-psicose in human intestine. Journal of Agricultural and Food Chemistry. 2013; 61(30): 7381-6.

33. Douard V, Ferraris RP. Regulation of the fructose transporter GLUT5 in health and disease. American Journal of Physiology-Endocrinology and Metabolism. 2008; 295: 227-7.

34. Harada M, Kondo E, Hayashi H, Suezawa C, Suguri $\mathrm{S}$, Arai $\mathrm{M}$, et al. D-Allose and D-psicose reinforce the action of metronidazole on trichomonad. Parasitology Research. 2012; 110(4): 1565-7.

35. Chung YM, Lee JH, Kim DY, Hwang SH, Hong YH, Kim SB. Dietary D-psicose reduced visceral fat mass in high-fat diet-induced obese rats. Journal of Food Science. 2012; 77(2): 53-8.

36. Yagi K, Matsuo T. The study on long-term toxicity of D-psicose in rats. Journal of Clinical Biochemistry and Nutrition. 2009; 45(3): 271-7.

37. Nagata Y, Kanasaki A, Tamaru S, Tanaka K. DPsicose, an epimer of D-fructose favorably alters lipid metabolism in sprague-dawley rats. Journal of Agricultural and Food Chemistry. 2015; 63(12): 3168-76.

38. Roncero I, Alvarez E, Chowen JA, Sanz C, Rabano A, Vazquez P. Expression of glucose transporter isoform GLUT-2 and glucokinase genes in human brain. Journal of Neurochemistry. 2004; 88(5): 120310.

39. Funari VA, Herrera VL, Freeman D, Tolan DR. Genes required for fructose metabolism are expressed in Purkinje cells in the cerebellum. Molecular Brain Research. 2005; 142(2): 115-22.

40. Matschinsky FM. Assessing the potential of glucokinase activators in diabetes therapy. Nature Reviews Drug Discovery. 2009; 8(5): 399-16.

41. Toyoda Y, Ito Y, Tanigawa K, Miwa I. Impairment of glucokinase translocation in cultured hepatocytes from OLETF and GK rats, animal models of type 2 diabetes. Archives of Histology and Cytology. 2000; 63(3): 243-8.

42. Herling AW, Burger HJ, Schwab D, Hemmerle H, Below P, Schubert G. Pharmacodynamic profile of a novel inhibitor of the hepatic glucose-6-phosphatase system. American Journal of Physiology. 1998; 274(6): 1087-93.

43. Shiota M, Moore MC, Galassetti P, Monohan M, Neal DW, Shulman GI. Inclusion of low amounts of fructose with an intraduodenal glucose load markedly reduces postprandial hyperglycemia and hyperinsulinemia in the conscious dog. Diabetes. 2002; 51(2): 469-78.

44. Watford M. Small amounts of dietary fructose dramatically increase hepatic glucose uptake through a novel mechanism of glucokinase activation. Nutrition Reviews. 2002; 60(8): 253-7.

45. Raushel FM, Cleland WW. Bovine liver fructokinase: Purification and kinetic properties. Biochemistry. 1977; 16(10): 2169-75.

46. Toyoda Y, Mori S, Umemura N, Futamura Y, Inoue H, Harta T. Suppression of blood glucose levels by Dpsicose in glucose tolerance test in diabetic rats. Japan Pharmacology \& Therapeutics. 2010; 38: 261-9.

47. Jong-Beom PARK, KIM KI, Eun-Young PARK. Increased Apoptosis, Expression of Matrix Degrading 
Enzymes and Inflammatory Cytokines of Annulus Fibrosus Cells in Genetically Engineered Diabetic Rats: Implication for Intervertebral Disc Degeneration. Journal of Neurological Sciences. 2016; 33(3): 415-23.

48. Schulze MB, Manson JE, Ludwig DS, Colditz GA, Stampfer MJ, Willett WC. Sugar-sweetened beverages, weight gain, and incidence of type 2 diabetes in young and middle-aged women. JAMA. 2004; 292(8): 927-34.

49. Choi BR, Kwon EY, Kim HJ, Choi MS. role of synbiotics containing d-allulose in the alteration of body fat and hepatic lipids in diet-1nduced obese mice. Nutrients. 2018;10(11): 1797.

50. Rutledge AC, Adeli K. Fructose and the metabolic syndrome: Pathophysiology and molecular mechanisms. Nutrition Reviews. 2007; 65: 13-23.

51. Hossain A, Yamaguchi F, Matsunaga T, Hirata Y, Kamitori K, Dong Y. Rare sugar D-psicose protects pancreas beta-islets and thus improves insulin resistance in OLETF rats. Biochemical and Biophysical Research Communications. 2012; 425(4): 717-23.

52. Ochiai M, Onishi K, Yamada T, Yamada T, Matsuo T. D-Psicose increases energy expenditure and decreases body fat accumulation in rats fed a highsucrose diet. International Journal of Food Sciences and Nutrition. 2014; 65(2): 245-50.

53. Kim SE, Kim SJ, Kim HJ, Sung MK. D-Psicose, a sugar substitute, suppresses body fat deposition by altering networks of inflammatory response and lipid metabolism in C57BL/6J-ob/ob mice. Journal of Functional Foods. 2017; 28: 265-74.

54. Baek SH, Park SJ, Lee HG. D-Psicose, a sweet monosaccharide, ameliorate hyperglycemia, and dyslipidemia in C57BL/6J db/db mice. Journal of Food Science. 2010; 75(2): 49-53.

55. Matsuo T, Baba Y, Hashiguchi M, Takeshita K, Izumori $\mathrm{K}$, suzuki $\mathrm{H}$, et al. Less body fat accumulation with $\mathrm{D}$-psicose diet versus $\mathrm{D}$-fructose diet. Journal of clinical biochemistry and nutrition. 2001; 30: 55-65.

56. Matsuo T, Tanaka T, Hassiguchi M, İzumori $\mathrm{K}$, Suzuki H. Effects of Oral Acute Administration and Subchronic Feeding of Several Levels of D-Psicose in Rats. Journal of Nutritional Science and Vitaminology. 2002; 48(6): 512-6. 